\title{
ORIGINAL ARTICLE Perinatal risk factors in Tourette's and chronic tic disorders: a total population sibling comparison study
}

G Brander ${ }^{1}$, M Rydell ${ }^{2}$, R Kuja-Halkola ${ }^{2}$, L Fernández de la Cruz ${ }^{1}$, P Lichtenstein ${ }^{2}$, E Serlachius ${ }^{1,3}$, C Rück $^{1,3}$, C Almqvist $^{2,4}$, BM D’Onofrio ${ }^{5}$, $\mathrm{H}$ Larsson $^{2,6}$ and D Mataix-Cols ${ }^{1,3}$

Adverse perinatal events may increase the risk of Tourette's and chronic tic disorders (TD/CTD), but previous studies have been unable to control for unmeasured environmental and genetic confounding. We aimed to prospectively investigate potential perinatal risk factors for TD/CTD, taking unmeasured factors shared between full siblings into account. A population-based birth cohort, consisting of all singletons born in Sweden in 1973-2003, was followed until December 2013. A total of 3026861 individuals were identified, 5597 of which had a registered TD/CTD diagnosis. We then studied differentially exposed full siblings from 947942 families; of these, 3563 families included siblings that were discordant for TD/CTD. Perinatal data were collected from the Medical Birth Register and TD/CTD diagnoses were collected from the National Patient Register, using a previously validated algorithm. In the fully adjusted models, impaired fetal growth, preterm birth, breech presentation and cesarean section were associated with a higher risk of TD/CTD, largely independent from shared family confounders and measured covariates. Maternal smoking during pregnancy was associated with risk of TD/CTD in a dose-response manner but the association was no longer statistically significant in the sibling comparison models or after the exclusion of comorbid attention-deficit/hyperactivity disorder. A dose-response relationship between the number of adverse perinatal events and increased risk for TD/CTD was also observed, with hazard ratios ranging from 1.41 (95\% confidence interval $(\mathrm{Cl})$ : $1.33-1.50$ ) for one event to 2.42 (95\% Cl: $1.65-3.53)$ for five or more events. These results pave the way for future gene by environment interaction and epigenetic studies in TD/CTD.

Molecular Psychiatry (2018) 23, 1189-1197; doi:10.1038/mp.2017.31; published online 28 March 2017

\section{INTRODUCTION}

Family $^{1-5}$ and molecular ${ }^{4,6-8}$ genetic studies suggest that Tourette's disorder (TD) and chronic tic disorders (CTD) are both familial and highly heritable conditions. There is growing evidence that environmental factors are also important in the etiology of these disorders, ${ }^{9}$ with at least $23 \%$ of the variance being explained by non-shared environmental factors. ${ }^{1}$ In addition, emerging evidence suggests potential epigenetic mechanisms in TD/CTD. ${ }^{10,11}$ With much of the current research focusing on the identification of common and rare genetic variants involved in TD/ CTD, ${ }^{8,12,13}$ there is a particular need to identify robust environmental risk factors implicated in these disorders, as some of these factors may be malleable or preventable.

Perinatal risk factors are a logical starting point because they are already known to be associated with a range of neuropsychiatric disorders, such as schizophrenia, ${ }^{14}$ bipolar disorder, ${ }^{15,16}$ autism spectrum disorder, ${ }^{17,18}$ attention-deficit/hyperactivity disorder (ADHD), ${ }^{18,19}$ and obsessive-compulsive disorder (OCD). ${ }^{20}$ Previous research on the association between adverse perinatal events and TD/CTD has been sparse and methodologically limited, resulting in inconclusive findings. ${ }^{9,21}$

Maternal smoking during pregnancy has been the focus of previous investigations, with conflicting results. For example, a recent Danish prospective population-based study ${ }^{22}$ including 531 TD/CTD patients reported an association between heavy smoking
(>10 cigarettes) during pregnancy and a $71 \%$ increased risk of TD/CTD, after controlling for a wide range of potential confounders, including birth weight and preterm birth. Maternal smoking during pregnancy has also been associated with TD severity. ${ }^{23}$ However, other studies did not find any association between maternal smoking during pregnancy and TD/CTD, ${ }^{24-26}$ including a longitudinal study of 6090 children from a pre-birth cohort, 122 of which had TD/CTD. ${ }^{25}$ Other studies only found such association in TD cases with comorbid ADHD. ${ }^{27-29}$

In two small studies involving monozygotic twin pairs, lower birth weight was associated with both the presence ${ }^{30}$ and the severity ${ }^{31}$ of TD. In addition, TD/CTD have been associated with premature birth, ${ }^{26}$ inadequate weight gain, ${ }^{25}$ low birth weight and preterm birth with comorbid $\mathrm{ADHD}^{29}$ birth complications, ${ }^{32}$ birth complications in males, ${ }^{33,34}$ older paternal age and low Apgar scores. $^{35}$ In addition, the severity of TD/CTD symptoms has been associated with delivery complications, ${ }^{24}$ and paternal age and negatively associated with birth weight. ${ }^{23}$ However, a number of other studies have failed to find such associations. ${ }^{23,25,27}$

All previous studies of perinatal risk factors in TD/CTD were based on relatively small samples, ascertained from specialist TD/CTD clinics and largely relied on retrospectively collected information on perinatal risk factors-except for Browne et al. ${ }^{22}$ and Mathews et al., ${ }^{25}$ which analyzed longitudinal data. Crucially, previous studies could not control for unmeasured familial

\footnotetext{
${ }^{1}$ Department of Clinical Neuroscience, Centre for Psychiatry Research, Karolinska Institutet, Stockholm, Sweden; ${ }^{2}$ Department of Medical Epidemiology and Biostatistics, Karolinska Institutet, Stockholm, Sweden; ${ }^{3}$ Stockholm Health Care Services, Stockholm County Council, Stockholm, Sweden; ${ }^{4}$ Astrid Lindgren Children's Hospital, Karolinska University Hospital, Stockholm, Sweden; ${ }^{5}$ Department of Psychological and Brain Sciences, Indiana University, Bloomington, IN, USA and ${ }^{6}$ Department of Medical Sciences, Örebro University, Örebro, Sweden. Correspondence: G Brander, Department of Clinical Neuroscience, Centre for Psychiatry Research, Karolinska Institutet, Gävlegatan 22B, Stockholm 113 30, Sweden.

E-mail: gustaf.brander@ki.se

Received 14 October 2016; revised 15 December 2016; accepted 9 January 2017; published online 28 March 2017
} 
confounders, which could result in spurious associations between perinatal events and TD/CTD. ${ }^{36}$

In this large-scale longitudinal population-based cohort study, we aimed to explore the potential causal link between a wide range of perinatal risk factors and TD/CTD. We employed a quasiexperimental family-based design to provide a better control for unmeasured environmental and genetic factors. Specifically, comparison of full siblings discordant for the exposure automatically controls for most shared environmental and a substantial proportion of genetic factors. ${ }^{37}$ Because some adverse perinatal events have been associated with comorbid disorders, ${ }^{26}$ we performed sensitivity analyses controlling for a range of comorbid disorders to isolate TD/CTD-specific risk factors. Finally, as there is some evidence that perinatal risk factors may act in a gender-specific manner, ${ }^{33,34}$ we also examined male and female patients separately.

\section{MATERIALS AND METHODS}

The study was approved by the Regional Ethical Review Board in Stockholm (reference number 2013/862-31/5). The requirement for informed consent was waived because the study was register-based and the included individuals were not identifiable at any time.

\section{Study population}

The study cohort consisted of all live singleton births in Sweden from 1 January 1973 to 31 December 2003. The cohort was followed from birth until first diagnosis of TD/CTD, emigration, death or end of follow-up (31 December 2013), whichever came first. The data were obtained by linking individuals through their unique personal identification numbers ${ }^{38}$ from the following population-based registers: (1) the Medical Birth Register (MBR), which includes data on more than $99 \%$ of all pregnancies and deliveries in Sweden since $19733^{39}$ (2) the Multi-Generation Register (MGR), with information about kinship going back to 1932, containing information on $100 \%$ of mothers and $98 \%$ of fathers of individuals born after $1961 ;{ }^{40}(3)$ the Swedish National Patient Register (NPR), which covers inpatient hospital admissions since 1969 and outpatient specialist care since $2001 i^{41}$ (4) the Migration Register, providing information about migration in and out of Sweden; ${ }^{42}$ and (5) the Cause of Death Register, with information on dates and causes of all deaths since $1961 .{ }^{43}$ Information from the Cause of Death Register and the Migration Register was used to calculate censoring time. For the sibling comparison analysis, we identified from the MGR a subsample of families with at least two full siblings (that is, siblings sharing the same biological mother and father) during the same time period.

\section{Exposures}

Information about all perinatal exposures was retrieved from the MBR. In this study, unless otherwise specified, we employed data from 1973 until 2003.

Maternal smoking during pregnancy. Information on maternal smoking during pregnancy collected at the first antenatal visit is available in the MBR from 1982, marking the start of cohort inclusion for this exposure ( $n=2152848)$. The variable was categorized as no daily smoking, 1-9 cigarettes per day and 10 or more cigarettes per day.

Labor presentation. Labor presentation was divided into normal presentation, breech and other malpresentations (for example, face or brow presentations or transverse lie).

Obstetric delivery. Obstetric delivery was categorized in three hierarchical categories: cesarean section, assisted (instrumental) vaginal delivery (that is, use of forceps or vacuum extraction) and unassisted (normal) vaginal delivery.

Gestational age and birth weight. Gestational age was categorized into preterm birth (gestational age $<37$ weeks), term birth (37-41 weeks) and post-term birth ( $\geqslant 42$ weeks).

Birth weight was analyzed in two ways. First, as a continuous variable, where we included linear and quadratic terms, distributed as every $250 \mathrm{~g}$. Second, as an ordinal variable categorized into $\leqslant 2500 \mathrm{~g}$ (low birth weight),
2501-3500 g, 3501-4500 g (referent category) and >4500 g (high birth weight).

Small for gestational age and large for gestational age were defined as a birth weight of more than two standard deviations below and above the mean weight for gestational age, respectively, according to the Scandinavian fetal growth curve adjusted for sex. ${ }^{44}$

Apgar score. The Apgar score ${ }^{45}$ at $5 \mathrm{~min}$ after delivery was categorized as normal (a score of $\geqslant 7$ ) or abnormal $(<7)$. The Apgar score is a tool for evaluating heart rate, respiratory effort, reflex irritability, muscle tone and color after delivery, which are considered to be five useful indicators that could be determined easily without interfering with the care of the infant.

Head circumference. Small head circumference $(\mathrm{HC})$ was defined as the individuals whose $\mathrm{HC}$ was below the 10th centile for each gestational week, and large $\mathrm{HC}$ as those whose $\mathrm{HC}$ was above the 90th centile for each gestational week, according to the World Health Organization standards. ${ }^{46}$

\section{Outcome}

The first instance of a recorded TD or CTD diagnosis in the NPR constituted the outcome using the classification of the International Classification of Diseases (ICD) in its 8th (ICD-8 code 306.2), 9th (ICD-9 code 307C) and 10th versions (ICD-10 codes F95.0 (transient tic disorder), F95.1 (chronic motor or vocal tic disorder), F95.2 (TD), F95.8 (other tic disorders) or F95.9 (unspecified tic disorder)). Using a previously validated algorithm, ${ }^{47}$ individuals who have transient tics as their only or final diagnostic code within the same year of the initial diagnosis are considered diagnosis-free. Furthermore, individuals who receive an initial diagnosis of transient, other or unspecified tics are only included if they receive at least an additional diagnosis of a tic disorder, except if the last available diagnosis is of a transient tic disorder given within the same year of the initial diagnosis. This approach results in nearly perfect inter-rater reliability and highly valid diagnoses, with a positive predictive value of 0.89 in ICD-8, 0.86 in ICD-9 and 0.97 in ICD-10. ${ }^{47}$

\section{Covariates}

Data on all potential, measured confounders were collected from the MBR (year of birth of the index person, sex, parity and maternal age at childbirth) and the MGR (paternal age at childbirth).

\section{Statistical analysis}

We performed Cox proportional hazards regression analysis to estimate hazard ratios (HR) and 95\% confidence intervals (CI) of the association between perinatal factors and TD/CTD.

We fitted three different Cox regression models for all exposure variables: first, we modeled the crude associations with TD/CTD, separately for each exposure variable; second, we adjusted for sex and year of birth; and third, in the fully adjusted model, we adjusted for all measured confounders, listed above.

For birth weight, we fitted both a linear and a quadratic representation. We used Akaike Information Criterion to determine which model (that is, linear or linear+quadratic) best fitted the data.

The analyses were also replicated in a fixed-effects model of the subsample of clusters of all full siblings using stratified Cox models. By design, these models adjust for shared familial confounders, ${ }^{48}$ in particular for genetic factors and unmeasured shared confounders, such as socioeconomic status and parental factors, that make siblings similar. Further, we adjusted for all measured confounders, all of which typically vary between full siblings.

To confirm that the associations were not entirely explained by comorbid conditions, we performed sensitivity analyses in subgroups where all individuals with certain comorbid conditions were excluded from analysis. These conditions were organized in six clusters: organic disorders (organic brain disorder and epilepsy), psychotic disorders (schizophrenia and bipolar disorder), OCD, ADHD, pervasive developmental disorders and mental retardation. All disorders were defined as at least one registered diagnosis in the NPR (for ICD codes, Supplementary Table 1). These models adjusted for all measured confounders. To investigate potential differences in risk factors between the sexes, we also ran all models separately by sex.

Finally, a Cox regression analysis was used to determine possible doseresponse effects, that is, the association between the accumulated number of adverse perinatal events that remained statistically significant in the fully adjusted models, and the risk for TD/CTD. 
All analyses were conducted using SAS statistical software, version 9.4 (SAS Institute, Cary, NC, USA).

\section{RESULTS}

Descriptive statistics

Descriptive characteristics of the study population are presented in Table 1. In total, 3026861 individuals were included in the cohort, 5597 of which were diagnosed with TD/CTD during the study period, resulting in a Kaplan-Meier estimated prevalence of $0.26 \%$ by age 40 (Supplementary Figure 1). As expected, individuals with TD/CTD were more likely to be male and to have multiple comorbidities, particularly other neuropsychiatric disorders and OCD (Table 1). Of the 947942 families with at least two children, 3563 families included full siblings discordant for TD/ CTD. This means that the family includes at least two children and at least one of them has a TD/CTD diagnosis and at least one does not.

Maternal smoking during pregnancy

In the fully adjusted model, maternal smoking during pregnancy was associated with an increased risk of offspring with TD/CTD in a dose-response manner (1-9 cigarettes $\mathrm{HR}=1.40(95 \% \mathrm{Cl}$ : $1.29-1.52)$ and $\geqslant 10$ cigarettes $\mathrm{HR}=1.88$ (95\% Cl: 1.71-2.06); Table 2). However, this association did not remain when familial factors were controlled for in the full sibling comparison (1-9 cigarettes $\mathrm{HR}=0.72$ (95\% Cl: $0.54-0.96)$ and $\geqslant 10$ cigarettes $\mathrm{HR}=0.79(95 \% \mathrm{Cl}: 0.55-1.15))$.

\section{Labor presentation}

An association was observed between breech presentation and an increased risk for TD/CTD in the fully adjusted model $(H R=1.17$ (95\% Cl: 1-1.38)), compared with normal presentation. The estimate increased further in the sibling comparison, but with lower precision ( $\mathrm{HR}=1.45$ (95\% Cl: 0.96-2.20); Table 2). In the unadjusted and adjusted models, no association between other malpresentations and TD/CTD was observed.

Obstetric delivery

There was an increased risk of TD/CTD among individuals delivered with cesarean section, compared with an unassisted vaginal delivery, in the fully adjusted model ( $\mathrm{HR}=1.22$ (95\% Cl: 1.13-1.32); Table 2). The results of the sibling comparison yielded a slightly lower and less precise estimate ( $\mathrm{HR}=1.15(95 \% \mathrm{Cl}$ : 0.91-1.46)). The association between assisted vaginal delivery and TD/CTD observed in the unadjusted model decreased in the adjusted models, and did not remain statistically significant in the sibling comparison.

\section{Gestational age}

Compared with those born at term, the risk for TD/CTD in individuals with preterm births ( $<37$ weeks) was significantly higher $(\mathrm{HR}=1.25(95 \% \mathrm{Cl}: 1.13-1.32))$. The results of the sibling comparison yielded a slightly lower and less precise estimate $(\mathrm{HR}=1.20$ (95\% Cl: 0.93-1.56)). Post-term births were not associated with an increased risk of TD/CTD (Table 2).

\section{Birth weight}

Birth weights below normal were associated with a slightly increased risk for TD/CTD when adjusting for all measured confounders as well as gestational age - known to correlate with birth weight ${ }^{49}(\leqslant 2500 \mathrm{~g}$ $\mathrm{HR}=1.26(95 \% \mathrm{Cl}: 1.06-1.51)$ and $2501-3500 \mathrm{~g} \mathrm{HR}=1.12(95 \% \mathrm{Cl}:$ 1.06-1.19); Table 2). The continuous representation mirrored these results (Figure 1). The results from the sibling comparison models yielded estimates with lower precision, with slightly lower estimates for $\leqslant 2500 \mathrm{~g}$ and slightly higher estimates for $2501-3500 \mathrm{~g}(\mathrm{HR}=1.20$
Table 1. Descriptive characteristics of study population separately for individuals with and without TD/CTD

\begin{tabular}{|c|c|c|}
\hline Variable & $\begin{array}{c}\text { Individuals without } \\
T D / C T D, \mathrm{n}(\%) \\
\mathrm{n}=3021264 \text { (99.82) }\end{array}$ & $\begin{array}{c}\text { Individuals with TD/ } \\
\text { CTD, } \mathrm{n}(\%) \\
\mathrm{n}=5597(0.18)^{\mathrm{a}}\end{array}$ \\
\hline $\begin{array}{l}\text { Mean follow-up time in } \\
\text { years } \pm \text { s.d. }{ }^{\text {b }}\end{array}$ & $25 \pm 9.25$ & $14.48 \pm 6.71$ \\
\hline \multicolumn{3}{|l|}{$\operatorname{Sex}^{\mathrm{b}}$} \\
\hline Males & 1551468 (51.35) & 4437 (79.27) \\
\hline Females & 1469796 (48.65) & $1160(20.73)$ \\
\hline $\begin{array}{l}\text { Mean age of mothers at } \\
\text { birth of index person, } \\
\text { years } \pm \text { s.d. }{ }^{c}\end{array}$ & $28 \pm 5.13$ & $27.78 \pm 5.33$ \\
\hline Missing & $0(0)$ & $0(0)$ \\
\hline $\begin{array}{l}\text { Mean age of fathers at } \\
\text { birth of index person, } \\
\text { years } \pm \text { s.d. }\end{array}$ & $31.37 \pm 5.99$ & $31.35 \pm 6.40$ \\
\hline Missing & $23778(0.79)$ & $52(0.93)$ \\
\hline \multicolumn{3}{|l|}{ Parity ${ }^{\mathrm{b}}$} \\
\hline 1 & 1272651 (42.12) & 2702 (48.28) \\
\hline 2 & $1105644(36.60)$ & 1778 (31.77) \\
\hline 3 & $456494(15.11)$ & 741 (13.24) \\
\hline$\geqslant 4$ & $186475(6.17)$ & $376(6.72)$ \\
\hline Missing & $0(0)$ & $0(0)$ \\
\hline \multicolumn{3}{|l|}{ Smoking during pregnancy ${ }^{\mathrm{b}, \mathrm{d}}$} \\
\hline No daily smoking & 1562819 (72.76) & $3383(67.88)$ \\
\hline 1-9 cigarettes per day & $263063(12.25)$ & 739 (14.83) \\
\hline $\begin{array}{l}\geqslant 10 \text { cigarettes } \\
\text { per day }\end{array}$ & $153840(7.16)$ & $543(10.89)$ \\
\hline Missing & $168142(7.83)$ & $319(6.40)$ \\
\hline \multicolumn{3}{|l|}{ Labor presentation } \\
\hline Normal presentation & 2201726 (72.87) & $4117(73.56)$ \\
\hline Breech presentation & $70874(2.35)$ & $152(2.72)$ \\
\hline Other malpresentation & $98144(3.25)$ & $184(3.29)$ \\
\hline Missing & $650520(21.53)$ & $1144(20.44)$ \\
\hline \multicolumn{3}{|l|}{ Obstetric delivery ${ }^{\mathrm{b}}$} \\
\hline $\begin{array}{l}\text { Unassisted vaginal } \\
\text { delivery }\end{array}$ & 2417839 (80.03) & $4179(74.66)$ \\
\hline Cesarean section & $33275(11.10)$ & $788(14.08)$ \\
\hline $\begin{array}{l}\text { Assisted vaginal } \\
\text { delivery }\end{array}$ & $189009(6.26)$ & $412(7.36)$ \\
\hline Missing & $79141(2.62)$ & $218(3.89)$ \\
\hline \multicolumn{3}{|l|}{ Gestational age } \\
\hline $\begin{array}{l}\text { Mean gestational age, } \\
\text { weeks } \pm \text { s.d. }^{\text {b }}\end{array}$ & $39.47 \pm 1.87$ & $39.34 \pm 1.96$ \\
\hline \multicolumn{3}{|l|}{ Gestational age $e^{\mathrm{b}}$} \\
\hline $\begin{array}{l}\text { Preterm birth } \\
(<37 \text { weeks })\end{array}$ & $150633(4.99)$ & $354(6.32)$ \\
\hline $\begin{array}{l}\text { Term birth } \\
\text { ( } 37-41 \text { weeks) }\end{array}$ & 2597377 (85.97) & $4759(85.03)$ \\
\hline $\begin{array}{l}\text { Post-term birth } \\
(\geqslant 42 \text { weeks })\end{array}$ & 265489 (8.79) & $473(8.45)$ \\
\hline Missing & $7765(0.26)$ & $11(0.20)$ \\
\hline \multicolumn{3}{|l|}{ Birth weight } \\
\hline $\begin{array}{l}\text { Mean birth weight, } \\
\mathrm{g} \pm \text { s.d. }\end{array}$ & $3524.71 \pm 557.88$ & $3523.97 \pm 582.73$ \\
\hline \multicolumn{3}{|l|}{ Birth weight ${ }^{c}$} \\
\hline$\leqslant 2500 \mathrm{~g}$ & 105449 (3.49) & $228(4.07)$ \\
\hline $2501-3500 \mathrm{~g}$ & 1323635 (43.81) & $2408(43.02)$ \\
\hline $3501-4500 \mathrm{~g}$ & $1484846(49.15)$ & $2738(48.92)$ \\
\hline$>4500 \mathrm{~g}$ & $98208(3.25)$ & $202(3.61)$ \\
\hline Missing & $9126(0.30)$ & $21(0.38)$ \\
\hline
\end{tabular}




\begin{tabular}{|c|c|c|}
\hline Variable & $\begin{array}{c}\text { Individuals without } \\
\text { TD/CTD, } \mathrm{n}(\%) \\
\mathrm{n}=3021264 \text { (99.82) }\end{array}$ & $\begin{array}{c}\text { Individuals with TD/ } \\
\text { CTD, } \mathrm{n}(\%) \\
\mathrm{n}=5597(0.18)^{\mathrm{a}}\end{array}$ \\
\hline \multicolumn{3}{|c|}{ Birth weight in relation to gestational age } \\
\hline $\begin{array}{l}\text { Small for gestational } \\
\text { age }^{c}\end{array}$ & $92677(3.07)$ & $217(3.88)$ \\
\hline $\begin{array}{l}\text { Normal for gestational } \\
\text { age }\end{array}$ & 2814340 (93.15) & $5195(92.17)$ \\
\hline $\begin{array}{l}\text { Large for gestational } \\
\text { age }\end{array}$ & $96548(3.20)$ & $184(3.29)$ \\
\hline Missing & $17699(0.59)$ & $37(0.66)$ \\
\hline \multicolumn{3}{|l|}{ Apgar score after 5 minutes } \\
\hline Normal, score $\geqslant 7$ & 2760313 (91.36) & 5356 (95.69) \\
\hline Abnormal, score $<7$ & $31282(1.04)$ & $59(1.06)$ \\
\hline Missing & $229669(7.60)$ & $182(3.25)$ \\
\hline \multicolumn{3}{|l|}{ Head circumference ${ }^{c}$} \\
\hline $\begin{array}{l}\text { Small head } \\
\text { circumference }(<10 \text { th } \\
\text { centile/gestational } \\
\text { week) }\end{array}$ & $136342(4.51)$ & $225(4.02)$ \\
\hline $\begin{array}{l}\text { Normal head } \\
\text { circumference }\end{array}$ & $2627690(86.97)$ & 4796 (85.69) \\
\hline $\begin{array}{l}\text { Large head } \\
\text { circumference (>90th } \\
\text { centile/gestational } \\
\text { week) }\end{array}$ & $162330(5.37)$ & $355(6.34)$ \\
\hline Missing & $94902(3.14)$ & $221(3.95)$ \\
\hline \multicolumn{3}{|l|}{ Comorbidity } \\
\hline Organic disorders $\mathrm{b}^{\mathrm{b}, \mathrm{f}}$ & $41619(1.38)$ & $313(5.59)$ \\
\hline Psychotic disorders ${ }^{\mathrm{b}, \mathrm{g}}$ & $31418(1.04)$ & $388(6.93)$ \\
\hline $\begin{array}{l}\text { Obsessive-compulsive } \\
\text { disorder }^{\text {b }}\end{array}$ & $18173(0.60)$ & $1036(18.51)$ \\
\hline $\mathrm{ADHD}^{\mathrm{b}}$ & $78398(2.59)$ & 2949 (52.69) \\
\hline $\begin{array}{l}\text { Pervasive } \\
\text { developmental } \\
\text { disorder }\end{array}$ & $34882(1.15)$ & $1611(28.78)$ \\
\hline Mental retardation ${ }^{\mathrm{b}}$ & $24734(0.82)$ & $459(8.20)$ \\
\hline $\begin{array}{l}\text { Affective and anxiety } \\
\text { disorders }{ }^{b, h}\end{array}$ & $238247(7.89)$ & $1810(32.34)$ \\
\hline \multicolumn{3}{|c|}{ 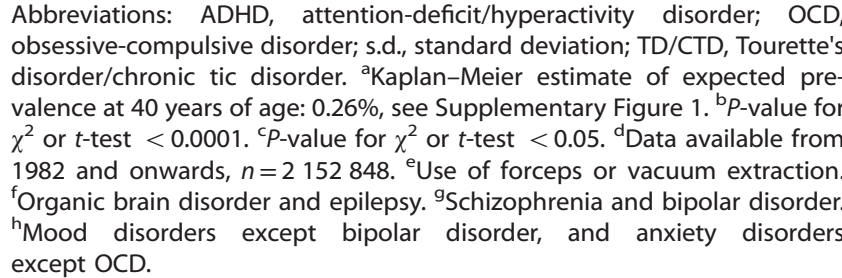 } \\
\hline
\end{tabular}

(95\% Cl: 0.80-1.80) and $\mathrm{HR}=1.23$ (95\% Cl: 1.07-1.41), respectively). High birth weight $(>4500 \mathrm{~g}$ ) was not associated with an increased risk for tics (Table 2).

Analyses of small for gestational age revealed an association with an increased risk for TD/CTD, both in the fully adjusted model and in the sibling comparison $(\mathrm{HR}=1.49$ (95\% Cl: $1.30-1.70)$ and $\mathrm{HR}=1.46$ (95\% Cl: 1.06-2.01), respectively), whereas large for gestational age revealed no such association (Table 2).

\section{Apgar score}

No statistically significant association between abnormal 5-min Apgar scores $(<7)$ and an increased risk for TD/CTD was observed (Table 2).
Head circumference

The observed statistically significant association between small HC and TD/CTD in the fully adjusted model ( $\mathrm{HR}=1.31$ (95\% Cl: 1.14-1.49)) did not remain in the sibling comparison $(H R=1.03$ (95\% Cl: 0.77-1.36); Table 2). No statistically significant association between large head circumference and TD/CTD was observed.

Number of perinatal events

A dose-response relationship between number of perinatal events and increased risk for TD/CTD was observed, with HRs ranging from 1.41 (95\% Cl: 1.33-1.50) for one event to 2.42 (95\% Cl: 1.653.53) for five or more events (Table 3 ).

Sensitivity analyses

The pattern of results remained largely unchanged in magnitude but with lower precision when individuals with comorbid conditions were excluded from the analyses, with the exception of ADHD, where both the magnitude and precision of the estimates tended to decrease for some of the examined risk factors (Table 4).

\section{Gender effects}

The pattern of results described above was similar in male and female individuals with TD/CTD, with overlapping Cls (Supplementary Table 2).

\section{DISCUSSION}

In this study of the entire Swedish population including over 5000 individuals diagnosed with TD/CTD, we found that maternal smoking during pregnancy, breech presentation, delivery by cesarean section, impaired fetal growth, preterm birth and small head circumference were associated with a higher risk of developing these disorders after adjusting for measured confounders. The sibling comparison analyses, which controlled for shared familial confounders, resulted in reduced precision (wider $\mathrm{Cls}$ ) but largely unchanged estimates for most perinatal variables. The exceptions to this were maternal smoking during pregnancy and small head circumference, which were no longer associated with TD/CTD in these sibling models. A dose-response relationship was identified for number of perinatal events, whereby the higher the number, the higher the risk for TD/CTD. Having one positive risk factor increased the risk of TD/CTD by $41 \%$, whereas having five or more risk factors more than doubled the risk, compared to having no adverse perinatal events.

An association between maternal smoking during pregnancy and TD/CTD has been inconsistently reported and likely confounded by the presence of comorbidities. ${ }^{23,27,28}$ We replicated recent findings from a Danish cohort study, which also identified a dose-response relationship between the number of cigarettes and the risk of TD/CTD. ${ }^{22}$ In our study, compared with the offspring of non-smoking mothers, offspring of mothers who reported smoking up to 9 cigarettes per day had a $40 \%$ increased risk of TD/CTD, whereas the offspring of heavy smokers $(\geqslant 10$ cigarettes/day) had an $88 \%$ increased risk. However, this association did not remain when controlling for shared familial confounders, which previous studies did not control for. These negative results are in line with other family-based studies suggesting that shared familial confounders explain why maternal smoking during pregnancy is associated with a range of psychosocial outcomes on the offspring (e.g., ADHD, criminality, academic achievement, drug use, adolescent antisocial behavior, adolescent psychological functioning, suicidal behavior, childhood conduct problems and intellectual abilities). ${ }^{37,50}$ OCD may be an exception to this general trend. ${ }^{20}$ 
Table 2. Hazard ratios and $95 \% \mathrm{Cls}$ of the association between perinatal events and TD/CTD

\begin{tabular}{|c|c|c|c|c|}
\hline Perinatal event & $\begin{array}{l}\text { Unadjusted model, HR } \\
\qquad(95 \% \mathrm{Cl})\end{array}$ & $\begin{array}{c}\text { Partially adjusted }{ }^{\mathrm{a}}, H R \\
(95 \% \mathrm{Cl})\end{array}$ & $\begin{array}{c}\text { Adjusted }^{\mathrm{b}}, H R(95 \% \\
\text { CI) }\end{array}$ & $\begin{array}{l}\text { Full sibling comparis } \\
\qquad(95 \% \mathrm{Cl})\end{array}$ \\
\hline \multicolumn{5}{|l|}{ Smoking during pregnancyc } \\
\hline No daily smoking & 1 & 1 & 1 & 1 \\
\hline 1-9 cigarettes per day & $1.17(1.08-1.27)$ & $1.48(1.37-1.60)$ & $1.40(1.29-1.52)$ & $0.72(0.54-0.96)$ \\
\hline$\geqslant 10$ cigarettes per day & $1.44(1.31-1.57)$ & $1.94(1.77-2.13)$ & $1.88(1.71-2.06)$ & $0.79(0.55-1.15)$ \\
\hline \multicolumn{5}{|l|}{ Labor presentation } \\
\hline Normal presentation & 1 & 1 & 1 & 1 \\
\hline Breech & $1.20(1.02-1.41)$ & $1.19(1.01-1.40)$ & $1.17(1-1.38)$ & $1.45(0.96-2.20)$ \\
\hline Other malpresentation & $1.00(0.86-1.16)$ & $1.02(0.88-1.18)$ & $1.00(0.86-1.16)$ & $1.18(0.82-1.69)$ \\
\hline \multicolumn{5}{|l|}{ Obstetric delivery } \\
\hline Unassisted vaginal delivery & 1 & 1 & 1 & 1 \\
\hline Cesarean section & $1.48(1.37-1.59)$ & $1.21(1.12-1.30)$ & $1.22(1.13-1.32)$ & $1.15(0.91-1.46)$ \\
\hline Assisted vaginal delivery & $1.32(1.19-1.46)$ & $1.08(0.98-1.20)$ & $1.02(0.92-1.13)$ & $0.91(0.71-1.15)$ \\
\hline \multicolumn{5}{|l|}{ Gestational age } \\
\hline Preterm birth ( $<37$ weeks) & $1.35(1.21-1.51)$ & $1.29(1.16-1.44)$ & $1.25(1.13-1.40)$ & $1.20(0.93-1.56)$ \\
\hline Term birth (37-41 weeks) & 1 & 1 & 1 & 1 \\
\hline Post-term birth ( $\geqslant 42$ weeks) & $0.92(0.84-1.01)$ & $1.05(0.95-1.15)$ & $1.03(0.93-1.13)$ & $1.03(0.84-1.26)$ \\
\hline \multicolumn{5}{|l|}{ Birth weight ${ }^{\mathbf{d}}$} \\
\hline$\leqslant 2500 \mathrm{~g}$ & $0.90(0.76-1.07)$ & $1.34(1.12-1.59)$ & $1.26(1.06-1.51)$ & $1.20(0.80-1.80)$ \\
\hline $2501-3500 \mathrm{~g}$ & $0.91(0.86-0.97)$ & $1.16(1.10-1.23)$ & $1.12(1.06-1.19)$ & $1.23(1.07-1.41)$ \\
\hline $3501-4500 \mathrm{~g}$ & 1 & 1 & 1 & 1 \\
\hline$>4500 \mathrm{~g}$ & $1.20(1.04-1.39)$ & $0.93(0.80-1.07)$ & $0.97(0.84-1.12)$ & $0.88(0.65-1.19)$ \\
\hline \multicolumn{5}{|l|}{ Birth weight in relation to gestational age } \\
\hline Not small for gestational age & 1 & 1 & 1 & 1 \\
\hline Small for gestational age & $1.25(1.09-1.43)$ & $1.54(1.34-1.76)$ & $1.49(1.30-1.70)$ & $1.46(1.06-2.01)$ \\
\hline Not large for gestational age & 1 & 1 & 1 & 1 \\
\hline Large for gestational age & $1.07(0.92-1.24)$ & $0.95(0.82-1.10)$ & $1(0.87-1.16)$ & $1.02(0.75-1.38)$ \\
\hline \multicolumn{5}{|l|}{ Apgar score after $5 \mathrm{~min}$} \\
\hline Normal, score $\geqslant 7$ & 1 & 1 & 1 & 1 \\
\hline Abnormal, score $<7$ & $1.13(0.88-1.46)$ & $1.13(0.87-1.46)$ & $1.10(0.85-1.42)$ & $0.86(0.48-1.54)$ \\
\hline \multicolumn{5}{|l|}{ Head circumference } \\
\hline $\begin{array}{l}\text { Small head circumference ( }<10 \text { th centile/ } \\
\text { gestational week) }\end{array}$ & $0.84(0.74-0.96)$ & $1.36(1.19-1.56)$ & $1.31(1.14-1.49)$ & $1.03(0.77-1.36)$ \\
\hline Normal head circumference & 1 & 1 & 1 & 1 \\
\hline Large head circumference ( $>$ 90th centile/ & $1.24(1.11-1.38)$ & $0.90(0.81-1.00)$ & $0.93(0.83-1.04)$ & $0.97(0.77-1.22)$ \\
\hline
\end{tabular}

gestational week)

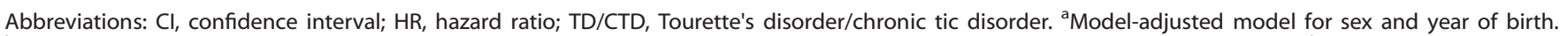
${ }^{\mathrm{b}}$ Model-adjusted for sex, year of birth, age of mother and father, and parity. ${ }^{\mathrm{C}}$ Data available from 1982 and onwards, $n=2152848 .{ }^{\mathrm{d}}$ Additionally adjusted for gestational age, both linear and quadratic terms in all models. Significant predictors are highlighted in bold.

Our results are in line with previous studies reporting an association between impaired fetal growth and birth complications and TD/CTD. ${ }^{23,24,26,30-32}$ However, other studies have failed to find such associations. ${ }^{23,25,27}$ Of note, all of this prior literature has used much smaller sample sizes than the current study (7-586 cases), likely to be insufficient to determine associations with rare perinatal exposures. In addition, two previous reports in clinical samples indicated that males with TD/CTD had more birth complications than females, ${ }^{33,34}$ a finding that we could not replicate in our study. It is possible that previous studies had insufficient number of female patients to test this hypothesis.

In general, the results remained unchanged when other frequent comorbidities were excluded from the analyses, with the exception of ADHD, where both the magnitude and precision of the estimates tended to be attenuated for some of the examined risk factors. Particularly the association with maternal smoking during pregnancy did not survive when excluding individuals with ADHD. However, over half of the individuals with
TD/CTD in our cohort had a comorbid ADHD diagnosis and their exclusion likely introduces a selection bias.

The mechanisms linking adverse perinatal factors and TD/CTD remain to be identified. Adverse fetal environments have been observed to affect brain development. ${ }^{51-53}$ Similarly, the fetal programming hypothesis posits that the adaptation to the fetal environment may lead to adverse effects in life. ${ }^{54,55}$ Neuroimaging studies have shown a relationship between structural and functional abnormalities within motor cortico-basal ganglia circuits and the occurrence of tics. ${ }^{56,57}$ Whereas genetic factors are indisputably important, an emerging body of literature is showing that environmental factors may have an important part in gene expression through epigenetic mechanisms. ${ }^{10}$ Recent findings from neuroimaging ${ }^{58}$ and transcriptome analyses studies of post-mortem brain tissue ${ }^{59}$ have linked TD with the activation of microglia brain cells following neuroinflammation. ${ }^{58-60}$

Many questions remain for the future, including whether and how adverse perinatal events interact with familial or genetic 


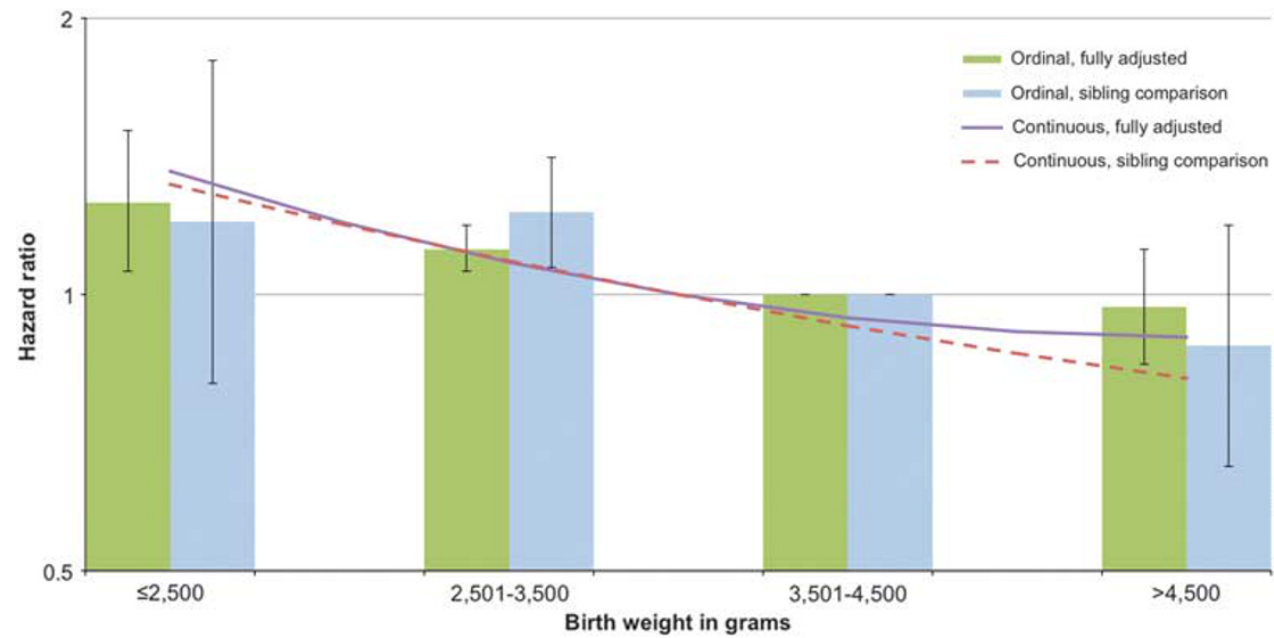

Figure 1. Hazard ratios and $95 \%$ confidence intervals $(\mathrm{Cls})$ of the association between birth weight and Tourette's disorder or chronic tic disorders (TD/CTD). Analysis of data as ordinal (columns) and continuous (lines) variables in fully adjusted, baseline, population-wide estimate and sibling comparison models for birth weight (reference group 3501-4500 g) in determination of the risk for TD/CTD in offspring born in Sweden between 1 January 1973 and 31 December 2003. Error bars indicate 95\% Cl. The $y$-axis uses a log scale.

\begin{tabular}{|c|c|c|c|c|c|}
\hline $\begin{array}{l}\text { Number of perinatal } \\
\text { events }^{a}\end{array}$ & $\begin{array}{c}\text { Individuals without TD/CTD, } \\
\mathrm{n}(\%)^{\mathrm{b}}\end{array}$ & $\begin{array}{c}\text { Individuals with } T D / C T D, \\
\mathrm{n}(\%)^{\mathrm{b}}\end{array}$ & $\begin{array}{l}\text { Unadjusted model, } H R \\
(95 \% \text { Cl) }\end{array}$ & $\begin{array}{c}\text { Partially adjusted }{ }^{c}, H R \\
(95 \% \mathrm{Cl})\end{array}$ & $\begin{array}{l}\text { Adjusted }^{\mathrm{d}}, H R \\
\quad(95 \% \mathrm{Cl})\end{array}$ \\
\hline 1 & $703282(23.28)$ & 1689 (30.18) & $1.55(1.46-1.64)$ & $1.45(1.37-1.54)$ & $1.41(1.33-1.50)$ \\
\hline 2 & 165930 (5.49) & $392(7.00)$ & $1.56(1.40-1.73)$ & 1.47 (1.33-1.64) & 1.43 (1.29-1.59) \\
\hline 3 & $54608(1.81)$ & $141(2.52)$ & 1.74 (1.47-2.06) & 1.74 (1.47-2.06) & 1.68 (1.42-1.99) \\
\hline \multicolumn{6}{|c|}{ 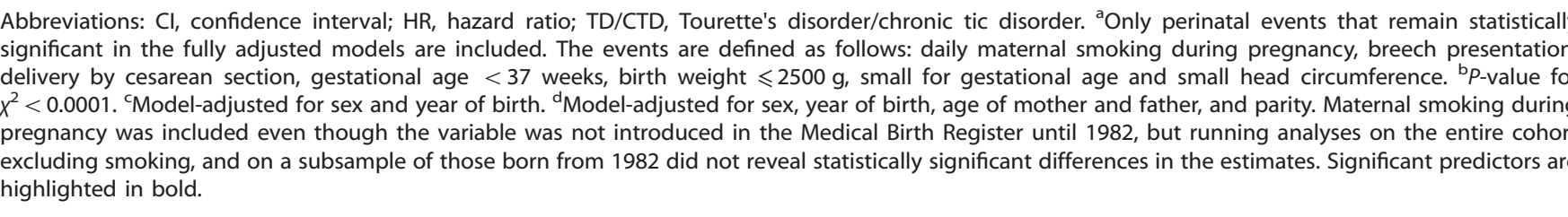 } \\
\hline
\end{tabular}

factors and whether perinatal complications predict the persistence of tics beyond young adulthood, alone or in interaction with genetic factors. Additional maternal factors, such as metabolic diseases during pregnancy or maternal immune activation, ${ }^{61}$ remain largely unexplored in TD/CTD.

\section{Strengths and limitations}

To the best of our knowledge, this is the first study examining a broad range of perinatal risk factors for TD/CTD using a very large population-based cohort with prospectively collected data at the time of birth. By comparing clusters of full siblings discordant for TD/CTD, we could control for many (unmeasured) shared familial confounders (genetic and environmental). In addition, the diagnostic validity and reliability of the TD/CTD diagnoses in the Swedish national registers is high. ${ }^{47}$

The results need to be interpreted in light of some study limitations. Our cohort is weighted towards more severe cases and does not represent the totality of all TD/CTD patients in Sweden. This is because many sufferers with mild symptoms may not seek help, the incomplete coverage of the outpatient register (which started in 2001 and had limited coverage in the early years), and that patients diagnosed by general practitioners, other nonspecialists or non-physicians are not included in the NPR. Some associations need to be interpreted with caution, as the small number of individuals being exposed to some events resulted in relatively imprecise estimates. Sibling comparisons can help inferring, but do not prove, causality. They also have lower statistical power than population-based estimates. ${ }^{48}$ Furthermore, sibling comparison designs are sensitive to random measurement error in the exposure, and may be biased due to variables shared by siblings that are related to the exposure but not the outcome. $^{37,62}$ The sibling comparison assumes there are no carryover effects from one pregnancy to a later pregnancy. ${ }^{63,64}$ Adjusting for parity addresses this partially, but not entirely.

\section{CONCLUSIONS}

A number of perinatal factors, namely impaired fetal growth, preterm birth, breech presentation and cesarean section are associated with a higher risk of TD/CTD, independently of shared family confounders and measured covariates, suggesting they may be in the causal pathway to TD/CTD. The association between maternal smoking during pregnancy and TD/CTD is likely to be 


\begin{tabular}{|c|c|c|c|c|c|c|}
\hline Perinatal event & $\begin{array}{l}\text { Excluding organic } \\
\text { disorders }^{\mathrm{a}}\end{array}$ & $\begin{array}{l}\text { Excluding psychotic } \\
\text { disorders }\end{array}$ & Excluding $O C D$ & Excluding $A D H D$ & $\begin{array}{c}\text { Excluding pervasive developmental } \\
\text { disorders }\end{array}$ & $\begin{array}{l}\text { Excluding mental } \\
\text { retardation }\end{array}$ \\
\hline \multicolumn{7}{|l|}{ Smoking during pregnancy ${ }^{\mathrm{C}}$} \\
\hline No daily smoking & 1 & 1 & 1 & 1 & 1 & 1 \\
\hline 1-9 cigarettes per day & $1.38(1.27-1.50)$ & $1.41(1.30-1.53)$ & $1.43(1.31-1.57)$ & $1.04(0.91-1.19)$ & $1.41(1.28-1.56)$ & $1.39(1.28-1.52)$ \\
\hline$\geqslant 10$ cigarettes per day & $1.87(1.70-2.06)$ & $1.89(1.72-2.08)$ & $2.05(1.86-2.27)$ & $1.18(0.99-1.39)$ & $1.87(1.67-2.10)$ & $1.88(1.70-2.08)$ \\
\hline \multicolumn{7}{|l|}{ Labor presentation } \\
\hline Normal presentation & 1 & 1 & 1 & 1 & 1 & 1 \\
\hline Breech & $1.19(1.01-1.40)$ & $1.16(0.98-1.38)$ & $1.24(1.04-1.48)$ & $1.17(0.93-1.48)$ & $1.09(0.89-1.33)$ & $1.10(0.93-1.31)$ \\
\hline Other malpresentation & $0.98(0.84-1.15)$ & $1.00(0.86-1.17)$ & $1.02(0.86-1.20)$ & $0.94(0.75-1.18)$ & $1.03(0.86-1.22)$ & $0.98(0.84-1.14)$ \\
\hline \multicolumn{7}{|l|}{ Obstetric delivery } \\
\hline Unassisted vaginal delivery & 1 & 1 & 1 & 1 & 1 & 1 \\
\hline Cesarean section & $1.19(1.10-1.29)$ & $1.19(1.10-1.29)$ & $1.26(1.15-1.37)$ & $1.16(1.03-1.30)$ & $1.21(1.11-1.33)$ & $1.19(1.09-1.29)$ \\
\hline Assisted vaginal delivery & $1.01(0.91-1.13)$ & $1.01(0.91-1.13)$ & $1(0.89-1.12)$ & $0.99(0.85-1.15)$ & $1.06(0.94-1.20)$ & $1.01(0.91-1.13)$ \\
\hline \multicolumn{7}{|l|}{ Gestational age } \\
\hline Preterm birth ( $<37$ weeks) & $1.24(1.11-1.39)$ & $1.25(1.12-1.40)$ & $1.24(1.10-1.39)$ & $1.18(1.00-1.38)$ & $1.15(1.01-1.32)$ & $1.24(1.11-1.39)$ \\
\hline Term birth (37-41 weeks) & 1 & 1 & 1 & 1 & 1 & 1 \\
\hline Post-term birth ( $\geqslant 42$ weeks) & $1.03(0.93-1.13)$ & $1.02(0.92-1.12)$ & $1.03(0.93-1.15)$ & $1.08(0.94-1.23)$ & $1.02(0.91-1.14)$ & $1.04(0.95-1.15)$ \\
\hline \multicolumn{7}{|l|}{ Birth weight ${ }^{\mathrm{d}}$} \\
\hline$\leqslant 2500 \mathrm{~g}$ & $1.29(1.07-1.54)$ & $1.27(1.06-1.52)$ & $1.23(1.00-1.50)$ & $1.30(1.00-1.67)$ & $1.21(0.97-1.49)$ & $1.21(1.00-1.46)$ \\
\hline $2501-3500 \mathrm{~g}$ & $1.11(1.04-1.18)$ & $1.11(1.04-1.18)$ & $1.15(1.08-1.23)$ & $1.06(0.98-1.16)$ & $1.10(1.02-1.18)$ & $1.11(1.04-1.18)$ \\
\hline $3501-4500 \mathrm{~g}$ & 1 & 1 & 1 & 1 & 1 & 1 \\
\hline$>4500 \mathrm{~g}$ & $0.99(0.85-1.14)$ & $0.97(0.84-1.13)$ & $1.03(0.88-1.20)$ & $0.87(0.70-1.09)$ & $0.94(0.79-1.11)$ & $0.95(0.81-1.10)$ \\
\hline \multicolumn{7}{|l|}{ Birth weight in relation to gestational age } \\
\hline Not small for gestational age & 1 & 1 & 1 & 1 & 1 & 1 \\
\hline Small for gestational age & $1.53(1.33-1.76)$ & $1.50(1.30-1.72)$ & $1.49(1.28-1.73)$ & $1.44(1.18-1.75)$ & $1.57(1.34-1.84)$ & $1.43(1.24-1.66)$ \\
\hline Not large for gestational age & 1 & 1 & 1 & 1 & 1 & 1 \\
\hline Large for gestational age & $1(0.86-1.17)$ & $1.01(0.86-1.17)$ & $1.04(0.89-1.22)$ & $0.97(0.78-1.21)$ & $0.96(0.80-1.14)$ & $1.02(0.87-1.19)$ \\
\hline \multicolumn{7}{|l|}{ Apgar score after $5 \mathrm{~min}$} \\
\hline Normal, score $\geqslant 7$ & 1 & 1 & 1 & 1 & 1 & 1 \\
\hline Abnormal, score $<7$ & $1.08(0.82-1.41)$ & $1.08(0.83-1.42)$ & $1.14(0.86-1.51)$ & $1.12(0.78-1.62)$ & $1.12(0.83-1.52)$ & $1.13(0.87-1.48)$ \\
\hline \multicolumn{7}{|l|}{ Head circumference $(\mathrm{cm})$} \\
\hline $\begin{array}{l}\text { Small head circumference }(<10 \text { th centile/ } \\
\text { gestational week) }\end{array}$ & $1.30(1.13-1.50)$ & $1.27(1.10-1.47)$ & $1.23(1.05-1.44)$ & $1.27(1.05-1.54)$ & $1.27(1.08-1.49)$ & $1.26(1.09-1.45)$ \\
\hline Normal head circumference & 1 & 1 & 1 & 1 & 1 & 1 \\
\hline $\begin{array}{l}\text { Large head circumference (>90th centile/ } \\
\text { gestational week) }\end{array}$ & $0.94(0.84-1.05)$ & $0.91(0.81-1.01)$ & $0.97(0.81-1.16)$ & $0.98(0.84-1.15)$ & $0.95(0.84-1.08)$ & $0.93(0.83-1.04)$ \\
\hline
\end{tabular}

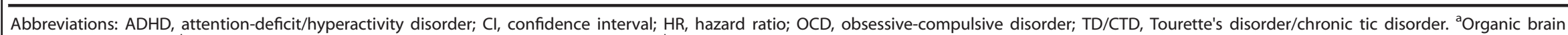
disorder and epilepsy. ${ }^{b}$ Schizophrenia and bipolar disorder. ' ${ }^{\top}$ Data available from $1982 .{ }^{d}$ Additionally adjusted for gestational age, both linear and quadratic terms. Significant predictors are highlighted in bold. 
spurious and explained by both familial factors and ADHD comorbidity. A dose-response relationship was also found, whereby the higher the number of perinatal events, the higher the risk for TD/CTD. These findings are important for the understanding of the etiology of TD/CTD and will hopefully inform future gene by environment interaction and epigenetic studies.

\section{CONFLICT OF INTEREST}

The authors declare no conflict of interest.

\section{ACKNOWLEDGMENTS}

G Brander is supported by a Karolinska Institutet PhD stipend (KID-funding). M Rydell reports a grant from the Swedish Research Council for Health, Working Life and Welfare (FORTE Grant Number 2015-00075). L Fernández de la Cruz reports grants from the David and Astrid Hagelén Foundation and the Swedish Research Council for Health, Working Life and Welfare (FORTE Grant Number 2015-00569). P Lichtenstein has served as a speaker for Medice. Catarina Almqvist acknowledges financial support from the Swedish Research Council through the Swedish Initiative for Research on Microdata in the Social And Medical Sciences (SIMSAM) framework Grant No. 340-2013-5867. C Rück is supported by a grant from the Swedish Research Council (K2013-61 P-22168). B D'Onofrio is supported by a grant from the Indiana Clinical and Translational Sciences Institute: Pediatric Development Team. H Larsson has served as a speaker for Eli-Lilly and Shire and has received a research grant from Shire; all outside the submitted work. Funders had no role in study design, data collection, data management, data analysis, data interpretation or writing of the report.

\section{REFERENCES}

1 Mataix-Cols D, Isomura K, Perez-Vigil A, Chang Z, Ruck C, Larsson KJ et al. Familial risks of Tourette syndrome and chronic tic disorders. A population-based cohort study. JAMA Psychiatry 2015; 72: 787-793.

2 Pauls DL, Raymond CL, Stevenson JM, Leckman JF. A family study of Gilles de la Tourette syndrome. Am J Hum Genet 1991; 48: 154-163.

3 Pauls DL, Towbin KE, Leckman JF, Zahner GE, Cohen DJ. Gilles de la Tourette's syndrome and obsessive-compulsive disorder. Evidence supporting a genetic relationship. Archiv Gen Psychiatry 1986; 43: 1180-1182.

4 Pauls DL, Fernandez TV, Mathews CA, State MW, Scharf JM. The inheritance of Tourette disorder: a review. J Obsessive Compuls Relat Disord 2014; 3: 380-385.

5 Pauls DL. The genetics of obsessive compulsive disorder and Gilles de la Tourette's syndrome. Psychiatr Clin North Am 1992; 15: 759-766.

6 Davis LK, Yu D, Keenan CL, Gamazon ER, Konkashbaev Al, Derks EM et al. Partitioning the heritability of Tourette syndrome and obsessive compulsive disorder reveals differences in genetic architecture. PLoS Genet 2013; 9: e1003864.

7 Paschou P. The genetic basis of Gilles de la Tourette syndrome. Neurosci Biobehav Rev 2013; 37: 1026-1039.

8 Scharf JM, Yu D, Mathews CA, Neale BM, Stewart SE, Fagerness JA et al. Genomewide association study of Tourette's syndrome. Mol Psychiatry 2013; 18: 721-728.

9 Hoekstra PJ, Dietrich A, Edwards MJ, Elamin I, Martino D. Environmental factors in Tourette syndrome. Neurosci Biobehav Rev 2013; 37: 1040-1049.

10 Pagliaroli L, Veto B, Aranyi T, Barta C. From genetics to epigenetics: new perspectives in Tourette syndrome research. Front Neurosci 2016; 10: 277.

11 Zilhao NR, Padmanabhuni SS, Pagliaroli L, Barta C, Smit DJ, Cath D et al. Epigenome-wide association study of tic disorders. Twin Res Hum Genet 2015; 18: 699-709.

12 Paschou P, Yu D, Gerber G, Evans P, Tsetsos F, Davis LK et al. Genetic association signal near NTN4 in Tourette syndrome. Ann Neurol 2014; 76: 310-315.

13 McGrath LM, Yu D, Marshall C, Davis LK, Thiruvahindrapuram B, Li B et al. Copy number variation in obsessive-compulsive disorder and tourette syndrome: a cross-disorder study. J Am Acad Child Adolesc Psychiatry 2014; 53: 910-919.

14 Schmitt A, Malchow B, Hasan A, Falkai P. The impact of environmental factors in severe psychiatric disorders. Front Neurosci 2014; 8: 19.

15 Chudal R, Sourander A, Polo-Kantola P, Hinkka-Yli-Salomaki S, Lehti V, Sucksdorff $\mathrm{D}$ et al. Perinatal factors and the risk of bipolar disorder in Finland. $J$ Affect Disord 2014; 155: 75-80.

16 D'Onofrio BM, Class QA, Rickert ME, Larsson H, Langstrom N, Lichtenstein P. Preterm birth and mortality and morbidity: a population-based quasiexperimental study. JAMA Psychiatry 2013; 70: 1231-1240.

17 Perrone-McGovern K, Simon-Dack S, Niccolai L. Prenatal and perinatal factors related to autism, IQ, and adaptive functioning. J Genet Psychol 2015; 176: 1-10.
18 Class QA, Rickert ME, Larsson H, Lichtenstein P, D'Onofrio BM. Fetal growth and psychiatric and socioeconomic problems: population-based sibling comparison. Br J Psychiatry 2014; 205: 355-361.

19 Hultman CM, Torrang A, Tuvblad C, Cnattingius S, Larsson JO, Lichtenstein P. Birth weight and attention-deficit/hyperactivity symptoms in childhood and early adolescence: a prospective Swedish twin study. J Am Acad Child Adolesc Psychiatry 2007; 46: 370-377.

20 Brander G, Rydell M, Kuja-Halkola R, Fernandez de la Cruz L, Lichtenstein P, Serlachius $E$ et al. Association of perinatal risk factors with obsessive-compulsive disorder: a population-based birth cohort, sibling control study. JAMA Psychiatry 2016; 73: 1135-1144.

21 Chao TK, Hu J, Pringsheim T. Prenatal risk factors for Tourette syndrome: a systematic review. BMC Pregnancy Childbirth 2014; 14: 53.

22 Browne HA, Modabbernia A, Buxbaum JD, Hansen SN, Schendel DE, Parner ET et al. Prenatal maternal smoking and increased risk for Tourette syndrome and chronic tic disorders. J Am Acad Child Adolesc Psychiatry 2016; 55: 784-791.

23 Mathews CA, Bimson B, Lowe TL, Herrera LD, Budman CL, Erenberg G et al. Association between maternal smoking and increased symptom severity in Tourette's syndrome. Am J Psychiatry 2006; 163: 1066-1073.

24 Bos-Veneman NG, Minderaa RB, Hoekstra PJ. The DRD4 gene and severity of tics and comorbid symptoms: main effects and interactions with delivery complications. Mov Disord 2010; 25: 1470-1476.

25 Mathews CA, Scharf JM, Miller LL, Macdonald-Wallis C, Lawlor DA, Ben-Shlomo Y. Association between pre- and perinatal exposures and Tourette syndrome or chronic tic disorder in the ALSPAC cohort. Br J Psychiatry 2014; 204: 40-45.

26 Abdulkadir M, Tischfield JA, King RA, Fernandez TV, Brown LW, Cheon KA et al. Pre- and perinatal complications in relation to Tourette syndrome and cooccurring obsessive-compulsive disorder and attention-deficit/hyperactivity disorder. J Psychiatric Res 2016; 82: 126-135.

27 Motlagh MG, Katsovich L, Thompson N, Lin H, Kim YS, Scahill L et al. Severe psychosocial stress and heavy cigarette smoking during pregnancy: an examination of the pre- and perinatal risk factors associated with ADHD and Tourette syndrome. Eur Child Adolesc Psychiatry 2010; 19: 755-764.

28 Leivonen S, Chudal R, Joelsson P, Ekblad M, Suominen A, Brown AS et al. Prenatal maternal smoking and tourette syndrome: a nationwide register study. Child Psychiatry Hum Dev 2016; 47: 75-82.

29 Pringsheim T, Sandor P, Lang A, Shah P, O'Connor P. Prenatal and perinatal morbidity in children with Tourette syndrome and attention-deficit hyperactivity disorder. J Dev Behav Pediatr 2009; 30: 115-121.

30 Leckman JF, Price RA, Walkup JT, Ort S, Pauls DL, Cohen DJ. Nongenetic factors in Gilles de la Tourette's syndrome. Archiv Gen Psychiatry 1987; 44: 100.

31 Hyde TM, Aaronson BA, Randolph C, Rickler KC, Weinberger DR. Relationship of birth weight to the phenotypic expression of Gilles de la Tourette's syndrome in monozygotic twins. Neurology 1992; 42: 652-658.

32 Saccomani L, Fabiana V, Manuela B, Giambattista R. Tourette syndrome and chronic tics in a sample of children and adolescents. Brain Dev 2005; 27: 349-352.

33 Eapen V, Fox-Hiley P, Banerjee S, Robertson M. Clinical features and associated psychopathology in a Tourette syndrome cohort. Acta Neurol Scand 2004; 109: 255-260.

34 Santangelo SL, Pauls DL, Goldstein JM, Faraone SV, Tsuang MT, Leckman JF. Tourette's syndrome: what are the influences of gender and comorbid obsessivecompulsive disorder? J Am Acad Child Adolesc Psychiatry 1994; 33: 795-804.

35 Burd L, Severud R, Klug MG, Kerbeshian J. Prenatal and perinatal risk factors for Tourette disorder. J Perinat Med 1999; 27: 295-302.

36 Thapar A, Rutter M. Do prenatal risk factors cause psychiatric disorder? Be wary of causal claims. Br J Psychiatry 2009; 195: 100-101.

37 D'Onofrio BM, Lahey BB, Turkheimer E, Lichtenstein P. Critical need for familybased, quasi-experimental designs in integrating genetic and social science research. Am J Public Health 2013; 103: S46-S55.

38 Ludvigsson JF, Otterblad-Olausson P, Pettersson BU, Ekbom A. The Swedish personal identity number: possibilities and pitfalls in healthcare and medical research. Eur J Epidemiol 2009; 24: 659-667.

39 Socialstyrelsen. The Swedish Medical Birth Register: a summary of content and quality. Available at: http://www.socialstyrelsen.se/Lists/Artikelkatalog/Attach ments/10655/2003-112-3_20031123.pdf. Accessed on 29 April 2016.

40 Ekbom A. The Swedish multi-generation register. Methods Mol Biol 2011; 675: 215-220.

41 Ludvigsson JF, Andersson E, Ekbom A, Feychting M, Kim JL, Reuterwall C et al. External review and validation of the Swedish national inpatient register. BMC Public Health 2011; 11: 450.

42 Ludvigsson JF, Almqvist C, Bonamy AK, Ljung R, Michaelsson K, Neovius M et al. Registers of the Swedish total population and their use in medical research. Eur J Epidemiol 2016; 31: 125-136.

43 Socialstyrelsen. Cause of death: 2013. Available at: http://www.socialstyrelsen.se/ statistics/statisticaldatabase/help/causeofdeath. Accessed on 29 April 2016. 
44 Marsal K, Persson PH, Larsen T, Lilja H, Selbing A, Sultan B. Intrauterine growth curves based on ultrasonically estimated foetal weights. Acta Paediatr 1996; 85: 843-848.

45 Apgar V. A proposal for a new method of evaluation of the newborn infant. Originally published in July 1953, volume 32, pages 250-259. Anesth Analg 2015; 120: 1056-1059.

46 World Health Organization. WHO Child Growth Standards: Head Circumference-forAge, Arm Circumference-for-Age, Triceps Skinfold-for-Age and Subscapular Skinfoldfor-Age: Methods and Development. World Health Organization: Geneva, 2007, $217 \mathrm{p}$.

47 Rück C, Larsson KJ, Lind K, Perez-Vigil A, Isomura K, Sariaslan A et al. Validity and reliability of chronic tic disorder and obsessive-compulsive disorder diagnoses in the Swedish National Patient Register. BMJ Open 2015; 5: e007520.

48 Allison PD. Fixed Effects Regression Models. Sage Publications: Thousand Oaks, CA, USA, 2009,123 p.

49 Oken E, Kleinman KP, Rich-Edwards J, Gillman MW. A nearly continuous measure of birth weight for gestational age using a United States national reference. BMC Pediatr 2003; 3: 6.

50 Kuja-Halkola R, D'Onofrio BM, Larsson H, Lichtenstein P. Maternal smoking during pregnancy and adverse outcomes in offspring: genetic and environmental sources of covariance. Behav Genet 2014; 44: 456-467.

51 Rees S, Inder T. Fetal and neonatal origins of altered brain development. Early Hum Dev 2005; 81: 753-761.

52 Huizink AC, Mulder EJ. Maternal smoking, drinking or cannabis use during pregnancy and neurobehavioral and cognitive functioning in human offspring. Neurosci Biobehav Rev 2006; 30: 24-41.

53 Schlotz W, Phillips DI. Fetal origins of mental health: evidence and mechanisms. Brain Behav Immun 2009; 23: 905-916.

54 Swanson JD, Wadhwa PM. Developmental origins of child mental health disorders. J Child Psychol Psychiatry 2008; 49: 1009-1019.

55 Barker DJ. In utero programming of chronic disease. Clin Sci 1998; 95: 115-128.

56 Worbe $Y$, Lehericy S, Hartmann A. Neuroimaging of tic genesis: present status and future perspectives. Mov disord 2015; 30: 1179-1183.
57 Ganos C, Roessner V, Munchau A. The functional anatomy of Gilles de la Tourette syndrome. Neurosci Biobehav Rev 2013; 37: 1050-1062.

58 Kumar A, Williams MT, Chugani HT. Evaluation of basal ganglia and thalamic inflammation in children with pediatric autoimmune neuropsychiatric disorders associated with streptococcal infection and tourette syndrome: a positron emission tomographic (PET) study using 11C-[R]-PK11195. J Child Neurol 2015; 30: 749-756.

59 Lennington JB, Coppola G, Kataoka-Sasaki Y, Fernandez TV, Palejev D, Li Y et al. Transcriptome analysis of the human striatum in Tourette syndrome. Biol Psychiatry 2016; 79: 372-382.

60 Martino D, Zis $P$, Buttiglione $M$. The role of immune mechanisms in Tourette syndrome. Brain Res 2015; 1617: 126-143.

61 Estes ML, McAllister AK. Maternal immune activation: implications for neuropsychiatric disorders. Science 2016; 353: 772-777.

62 Frisell T, Oberg S, Kuja-Halkola R, Sjolander A. Sibling comparison designs: bias from non-shared confounders and measurement error. Epidemiology 2012; 23: 713-720.

63 Sjolander A, Frisell T, Kuja-Halkola R, Oberg S, Zetterqvist J. Carry-over effects in sibling comparison designs. Epidemiology 2016; 27: 852-858.

64 Lahey BB, D'Onofrio BM. All in the family: comparing siblings to test causal hypotheses regarding environmental influences on behavior. Curr Dir Psychol Sci 2010; 19: 319-323.

(c) (i) $\odot$ This work is licensed under a Creative Commons AttributionBY NC ND NonCommercial-NoDerivs 4.0 International License. The images or other third party material in this article are included in the article's Creative Commons license, unless indicated otherwise in the credit line; if the material is not included under the Creative Commons license, users will need to obtain permission from the license holder to reproduce the material. To view a copy of this license, visit http:// creativecommons.org/licenses/by-nc-nd/4.0/

(c) The Author(s) 2018

Supplementary Information accompanies the paper on the Molecular Psychiatry website (http://www.nature.com/mp) 